\title{
TINGKAT ADOPSI INOVASI IB (INSEMINASI BUATAN) PADA PETERNAK SAPI POTONG DI KECAMATAN LALABATA KABUPATEN SOPPENG Adoption Of Innovation Ai ( Artificial Insemination) Breeder In Cattle In District Lalabata Soppeng
}

\author{
Angga Nugraha ${ }^{1}$, Agustina Abdullah ${ }^{2}$ dan Nurani Sirajuddin ${ }^{3}$ \\ ${ }^{1}$ Mahasiswa Jurusan Sosial Ekonomi Peternakan, Universitas Hasanuddin \\ ${ }^{2}$ Staf Pengajar Jurusan Sosial Ekonomi Peternakan, Universitas Hasanuddin \\ Email : anggasosek2010@yahoo.co.id
}

\section{ABSTRACT}

The purpose of this study was to determine the extent to which farmers in adopting the technology of artificial insemination by measuring the time it takes breeders from receipt of the information to be applied, the quality of AI (Application and recommendation), and Area Applied IB in cattle. The research was conducted in August - September 2014 against 30 respondents from 30 populations breeders who use technology AI (Artificial Insemination). Data were analyzed using descriptive statistics by using tables Distribution Frekuwensi results showed adoption rate of technological innovation Artificial Insemination ( AI) in beef cattle farms in the district Lalabata Soppeng ie Stage time is needed breeders from the receipt of the information to be obtained on application High category in the sense of the ability of farmers to adopt an innovation has been rapid, stage area located on the application of Low Category this suggests that the broad application of the implementation of the AI in the district as a whole Lalabata the breeder has done these activities, but not all animals in peliharanya apply technology Artificial Insemination (AI), and Phase AI quality is in the category Medium this suggests that the quality of AI in District Lalabata Soppeng ie almost entirely of farmers already know the signs of estrus in livestock before conducting AI.

\section{Keywords : Adoption Levels, Artificial Insemination, Beef Cattle Breeders}

Tujuan dari penelitian ini adalah untuk untuk mengetahui pada tingkatan mana peternak dalam mengadopsi teknologi inseminasi buatan dengan mengukur waktu yang dibutuhkan peternak mulai dari diterimanya informasi sampai diterapkan, mutu IB (Penerapan dan rekomendasi), dan Luas penerapan IB pada ternak. Penelitian ini dilaksanakan pada bulan Agustus - September 2014 terhadap 30 responden dari 30 populasi peternak yang menggunakan teknologi IB (Inseminasi Buatan). Data di analisis dengan menggunakan statistik deskriptif dengan menggunakan tabel Distribusi Frekuwensi Hasil penelitian menunjukkan Tingkat adopsi inovasi teknologi Inseminasi Buatan (IB) pada peternakan sapi potong di Kecamatan Lalabata Kabupaten Soppeng yaitu Tahap waktu yang di butuhkan peternak mulai dari diterimanya informasi sampai pada penerapannya di peroleh berada pada kategori Tinggi dalam arti kemampuan peternak dalam mengadopsi suatu inovasi tergolong cepat, Tahap Luas Penerapan berada pada Kategori Rendah Hal ini menunjukkan bahwa luas penerapan pada pelaksanaan kegiatan IB di kecamatan Lalabata yakni secara keseluruhan peternak sudah melakukan kegiatan tersebut namun tidak semua ternak yang di peliharanya menerapkan teknologi Inseminasi Buatan (IB), dan Tahap Mutu IB berada pada kategori Sedang Hal ini menunjukkan bahwa mutu IB di Kecamatan Lalabata Kabupaten Soppeng yakni hampir secara keseluruhan peternak sudah mengetahui tanda-tanda birahi pada ternaknya sebelum melakukan kegiatan IB

Kata kunci: Tingkat Adopsi, Inseminasi Buatan, Peternak Sapi Potong 


\section{PENDAHULUAN}

Pembangunan sub sektor peternakan di Indonesia diharapkan dapat meningkatkan produktivitas ternak. Salah satu upaya dalam meningkatkan produktivitas ternak adalah dengan menerapkan teknologi IB (Inseminasi Buatan). Inseminasi buatan merupakan teknologi alternatif yang sedang dikembangkan dalam usaha meningkatkan produktifitas biologik ternak lokal Indonesia melalui teknologi pemuliaan yang hasilnya relatif cepat dan cukup memuaskan serta telah meluas dilaksanakan adalah mengawinkan ternak tersebut dengan ternak unggul impor (Hastuti, 2008)

Inseminasi buatan (IB) merupakan salah satu teknologi dalam reproduksi ternak yang memiliki manfaat dalam mempercepat peningkatan mutu genetik ternak, mencegah penyebaran penyakit reproduktif yang ditularkan melalui perkawinan alam, meningkatkan efisiensi penggunaan pejantan unggul. Namun berhasil tidaknya pengembangan teknologi ditentukan oleh mau tidaknya petani mengadopsi teknologi yang dianjurkan sedangkan keputusan mengadopsi suatu teknologi banyak dipengaruhi sifat teknologi.

Salah satu kebupaten di Sulawesi Selatan yang menjadi pengembangan program Inseminasi Buatan (IB) adalah kabupaten Soppeng. Program ini sangat perlu dilakukan secara simultan dan terpadu antara pemerintah dan masyarakat petani peternak karena dapat meningkatkan pendapatan masyarakat petani peternak sehingga kesejahteraan masyarakat dapat terwujud. Kecamatan Lalabata kabupaten Soppeng merupakan salah satu kecamatan yang telah menerapkan program inseminasi buatan (IB).

Peternak di kecamatan Lalabata Kabupaten Soppeng dalam menerima dan mengadopsi teknologi IB memiliki berbagai tingkat adopsi, peternak menempati posisi masing-masing peternak di tingkat adopsi, oleh karena itu perlu diteliti posisi masingmasing peternak di tingkatan adopsi IB dan untuk mengetahui penyebab belum optimalnya adopsi IB di Kecamatan Lalabata Kabupaten Soppeng. Tujuan penelitian ini adalah untuk mengetahui tingkat adopsi teknologi IB (Inseminasi Buatan) pada peternak sapi potong di Kecamatan Lalabata Kabupaten Soppeng.

Kegunaan penelitian ini yaitu :

1. Sebagai bahan informasi bagi penyuluh peternakan dalam program peningkatan produktivitas ternak sapi potong khususnya penerapan teknologi IB (Inseminasi Buatan) di kecamatan Lalabata kabupaten Soppeng.

2. Sebagai bahan informasi dan pertimbangan bagi pihak pemerintah dalam mengambil kebijakan usaha peternakan sapi potong.

3. Sebagai bahan informasi bagi para peternak sapi potong yang belum menerapkan IB di kecamatan Lalabata kabupaten Soppeng

\section{MATERI DAN METODE PENELITIAN}

Penelitian ini dilakukan di Kecamatan Lalabata Kabupaten Soppeng. Lokasi ini dipilih karena sebagian besar peternak telah mengikuti program Inseminasi Buatan (IB). Jenis penelitian yang digunakan adalah penelitian kuantitatif deskriftif, yaitu jenis penelitian yang menjelaskan atau menggambarkan suatu fenomena penelitian sebagaimana adanya atau membahas suatu variabel tanpa melihat hubungan antara variabel satu dengan variabel yang lain. Populasi pada penelitian ini adalah semua peternak yang mengikuti program IB (Inseminasi Buatan) di kecamatan Lalabata 
Kabupaten Soppeng dengan jumlah 30 orang peternak, semua populasi diambil (Sampel Jenuh). Jenis data yang digunakan dalam penelitian ini yaitu data kualitatif dan data kuantitatif . Sumber data yaitu data primer data sekunder. Adapun teknik pengumpulan data yang digunakan dalam penelitian ini adalah wawancara, observasi, dan dokumentasi. Analisis data yang digunakan dalam penelitian ini adalah analisis statistik Deskriptif dengan menggunakan Tabel Distribusi Frekwensi dengan pengukuran memakai skala likert dengan pengukuran diberi skor dengan skala pengukuran 1,2, dan 3 (Riduwan,2002 : 12 - 16),

Selanjutnya untuk mengetahui keadaan peternak sapi potong yang ikut program Inseminasi Buatan (IB) di Kecamatan Lalabata dalam berbagai tingkat penerimaan adopsi maka variabel pengukurannya diberi skor dengan cara skoring dapat dilihat pada tabel 1.

Tabel 1. Variabel dan Indikator Pengukuran Penelitian

\begin{tabular}{|c|c|c|c|}
\hline No. & Variabel & Sub Variabel & Indikator Pengukuran \\
\hline \multirow{5}{*}{1 . } & \multirow{5}{*}{$\begin{array}{l}\text { Tingkat Adopsi } \\
\text { Teknologi IB } \\
\text { (Inseminasi } \\
\text { Buatan) }\end{array}$} & $\begin{array}{l}\text { - Waktu yang di } \\
\text { butuhkan petani mulai } \\
\text { dari di terimanya } \\
\text { informasi sampai } \\
\text { diterapkan }\end{array}$ & $\begin{array}{c}-(0-5 \text { Bulan }) \\
-(5-10 \text { Bulan }) \\
-(>10 \text { Bulan })\end{array}$ \\
\hline & & & -Sangat Tahu \\
\hline & & & -Tahu \\
\hline & & $\begin{array}{l}\text { - Mutu IB ( Penerapan dan } \\
\text { rekomendasi) }\end{array}$ & -Kurang Tahu \\
\hline & & $\begin{array}{l}\text { - Luas Penerapan IB pada } \\
\text { ternak }\end{array}$ & $\begin{array}{l}\text { - Secara keseluruhan } \\
\text { - Setengah } \\
\text { - Sedikit }\end{array}$ \\
\hline
\end{tabular}

Untuk mengetahui tingkat adopsi IB di Kecamatan Lalabata Kabupaten Soppeng dengan menggunakan asumsi dasar Interval, atau rentang kelas yaitu : sebagai berikut :

Skor tertinggi

Skor terendah

Rentang Kelas

$$
\begin{aligned}
& =3 \times 30=90 \text { point } \\
& =1 \times 30=30 \text { point } \\
& =\underline{\text { Angka tertinggi }- \text { Angka terendah }}
\end{aligned}
$$$$
3
$$

$$
\begin{aligned}
& =\frac{90-30}{3} \\
& =20 \text { point }
\end{aligned}
$$

Dari nilai di atas maka dapat dibuat suatu katetori Jawaban sebagai berikut:

Tinggi

: $70-90$

Sedang

: $50-69$

Rendah : $30-49$

Untuk mengetahui keseluruhan nilai dari seluruh peternak yang mengikuti program IB dalam tingkat adopsi IB di kecamatan Lalabata Kabupaten Soppeng dengan menggunakan asumsi dasar interval kelas atau rentang yaitu sebagai berikut :

Skor tertinggi $=$ Bobot tertinggi $\mathrm{x}$ Jumlah sampel $\mathrm{x}$ Jumlah pertanyaan

(3) 
Skor terendah $=$ Bobot terendah $\mathrm{x}$ Jumlah sampel $\mathrm{x}$ Jumlah pertanyaan

$\begin{aligned} & = & 90 \\ \text { Rentang kelas } & = & \frac{\text { Angka tertinggi }- \text { An }}{3} \\ & = & \frac{270-90}{3} \\ & = & 60\end{aligned}$

Dari nilai di atas maka dapat dibuat suatu kategori jawaban sebagai berikut :

1. Rendah

2. Sedang

3. Tinggi

$$
\begin{aligned}
& =90-149 \\
& =150-209 \\
& =210-270
\end{aligned}
$$

\section{HASIL DAN BAHASAN}

Untuk mengetahui bagaimana tingkat adopsi inovasi Teknologi Inseminasi Buatan (IB) pada peternakan sapi potong di Kecamatan Lalabata Kabupaten Soppeng, maka dapat dilihat berdasarkan frekuensi jawaban responden, sebagaimana dikemukakan sebagai berikut :

\section{Waktu yang dibutuhkan peternak dalam mengadopsi IB}

Waktu yang dibutuhkan adalah waktu yang dibutuhkan peternak mulai dari diterimanya informaasi sampai diterapkannya teknologi IB. Proses keputusan inovsasi memerlukan waktu, proses keputusan inovasi adalah proses yang di jalankan seseorang mulai dari tahu suatu inovasi kemudian menyikapinya lalu mengambil keputusan untuk mengadopsinya.

Berdasarkan hasil penelitian yang diperoleh tentang penilaian adopsi inovasi mengenai waktu yang di butuhkan di Kecamatan Lalabata Kabupaten Soppeng dapat dilihat pada table 2 .

Tabel 2. Penilaian Peternak Terhadap Adopsi Inovasi IB Mengenai Waktu Yang Dibutuhkan Petani Peternak

\begin{tabular}{lllllll}
\hline No & \multicolumn{2}{c}{ Indikator } & Skor & $\begin{array}{c}\text { Frekuensi } \\
\text { (Orang) }\end{array}$ & $\begin{array}{c}\text { Persentse } \\
(\mathbf{\%})\end{array}$ & Bobot \\
\hline 1. & Waktu & Yang Dibutuhkan & 3 & 21 & 70 & 63 \\
& Peternak & Mulai Dari Di & 2 & 7 & 23.3 & 14 \\
& Terimanya Informasi Sampai & 1 & 2 & 6,7 & 2 \\
& $\begin{array}{l}\text { Di Terapkannya IB diKec. } \\
\text { Lalabata Kab. Soppeng }\end{array}$ \\
\end{tabular}

Pada tabel 2, dapat dilihat bahwa total skor adopsi inovasi Teknologi Inseminasi Buatan (IB) pada peternakan sapi potong di Kecamatan Lalabata Kab. Soppeng yaitu sebesar 79, berada pada kategori Tinggi. Berdasarkan hasil tersebut diketahui bahwa kebanyakan peternak hanya membutuhkan waktu 0-5 bulan untuk mengadopsi teknologi inseminasi buatan (IB) dalam arti kemampuan peternak dalam mengadopsi suatu inovasi tergolong cepat,karena sebagian besar responden berada dalam usia produktif dan tingkat pendidikan di Kecamatan Lalabata tergolong tinggi, dimana tingkat pendidikan seseorang 
dapat berpengaruh terhadap cepat atau lambatnya peternak dalam mengadopsi suatu inovasi khususnya teknologi Inseminasi Buatan (IB), selain itu faktor yang mempengaruhi peternak di Kecamatan Lalabata kabuaten Soppeng mengadopsi inovasi inseminasi buatan yaitu intensitas kegiatan penyuluhan IB yang dilakukan minimal 3 kali dalam sebulan . Hal ini sesuai dengan pendapat Soekartawi (2005) yang menyatakan bahwa salah satu yang mempengaruhi adopsi inovasi yaitu intensitas penyuluhan. Penyuluh pertanian berperan sebagai pembawa misi menyampaikan ide, hal-hal baru kepada pihak pemakai yaitu petani beserta keluarganya. Semakin giat penyuluh mempromosikan suatu inovasi maka dapat diharapkan akan semakin tinggi tingkat dan kecepatan adopsi inovasi tersebut.

Gambar 1.Penilaian adopsi inovasi Teknologi Inseminasi Buatan (IB) mengenai waktu yang dibutuhkan petani peternak dari di terimanya informasi sampai penerapannya pada peternakan sapi bali di Kecamatan Lalabata Kab. Soppeng.

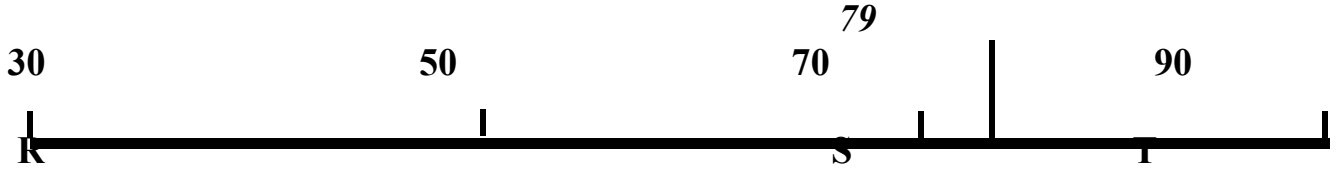

Keterangan :

$$
\begin{array}{ll}
\mathrm{R} & =\text { Rendah }(10 \text { bulan ke atas }) \\
\mathrm{S} & =\text { Sedang }(6-10 \text { bulan }) \\
\mathrm{T} & =\text { Tinggi }(0-5 \text { bulan })
\end{array}
$$

Pada gambar 1 Penilaian adopsi inovasi Teknologi Inseminasi Buatan (IB) mengenai waktu yang dibutuhkan petani peternak dari diterimanya informasi sampai penerapannya pada peternakan sapi potong di Kecamatan Lalabata Kab. Soppeng mendapatkan skor 79 berada diantara skor 70 dan skor 90 pada skala tinggi (0-5 bulan)

Hasil penelitian tersebut serupa dengan hasil penelitian (Demita, 2011) penelitian tingkat adopsi IB di kecamatan Kuranji yang menyimpulkan bahwa kecepatan/selang waktu antara diterimanya dan penerapan yang dilakukan antara lain : Peternak langsung menerapkan IB pada sapi potong setelah mendapat penyuluhan $(+)$ setuju besar $100 \%$ yang berarti bahwa peternak cepat dalam mengadopsi IB.

\section{Mutu IB (Inseminasi Buatan)}

Mutu IB dapat diketahui dengan cara membandingkan penerapan dengan rekomendasi yang disampaikan penyuluh dalam melihat tanda sapi yang berahi.

Berdasarkan hasil penelitian yang diperoleh tentang penilaian adopsi inovasi mengenai mutu IB pada kegiatan Inseminasi Buatan (IB) di Kecamatan Lalabata Kabupaten Soppeng dapat dilihat pada tabel 3.

Tabel 3. Penilaian Peternak Terhadap Adopsi Inovasi Mengenai Mutu IB pada kegiatan Inseminasi Buatan (IB) di Kec. Lalabata Kab. Soppeng

\begin{tabular}{lllll}
\hline No Indikator & Skor & $\begin{array}{l}\text { Frekuensi } \\
(\text { Orang) }\end{array}$ & $\begin{array}{l}\text { Persentse } \\
(\%)\end{array}$ & Bobot \\
\hline Total & 30 & 100 & 62 \\
\hline
\end{tabular}

Sumber : Data Primer Setelah Diolah, 2014

Pada tabel 3, dapat dilihat bahwa total skor adopsi inovasi Teknologi mengenai mutu IB pada kegiatan Inseminasi Buatan (IB) pada peternakan sapi potong di Kecamatan Lalabata Kabupaten Soppeng Soppeng yaitu sebesar 62 , berada pada kategori Sedang. Hal ini menunjukkan bahwa mutu IB di Kecamatan Lalabata Kabupaten Soppeng yakni 
hampir secara keseluruhan peternak sudah mengetahui tanda-tanda birahi pada ternaknya sebelum melakukan kegiatan IB.Hal ini di karenakanpengetahuan yang dimiliki peternak untuk mendeteksi tanda-tanda berahi sudah baik karena intensitas kegiatan penyuluhan yang dilakukan di Kecamatan Lalabata kabupaten Soppengsering dilakukan dan faktor lainnya yaitu peranan inseminator dalam membimbing secara langsung peternak didalam mendeteksi ternak yang birahi, hal ini sesuai dengan pendapat Rogers (1971) bahwa penyuluhan sebagai salah satu faktor yang mempengaruhi tingkat adopsi, dimana penyuluh berperan aktif dalam menyebarkan inovasi kedalam suatu sistem sosial,

Program penyuluhan membantu seseorang meningkatkan pengetahuan mereka dalam aspek teknik dalam pertanian dan pemahaman mereka secara proses biologis, fisik, dan ekonomi dalam pertanian, dan hal ini didukung oleh Herawati (2012) menyatakan bahwa inseminasi buatan (IB) atau kawin suntik adalah upaya memasukkan semen/mani ke dalam saluran reproduksi hewan betina yang sedang birahi dengan bantuan inseminator agar hewan bunting. Dari definisi ini inseminator berperan sangat besar dalam keberhasilan pelaksanaan IB. Keahlian dan keterampilan inseminator dalam akurasi pengenalan berahi, sanitasi alat, penanganan (handling) semen beku, pencairan kembali (thawing) yang benar, serta kemampuan melakukan IB akan menentukan keberhasilan. Untuk lebih jelasnya penilaian mutu IB pada kegiatan Inseminasi Buatan (IB)peternakan sapi bali di Kecamatan Lalabata Kabupaten Soppeng dapat di lihat pada gambar 2.

Gambar 2. Penilaian adopsi inovasi Teknologi Buatan (IB) mengenai mutu IB pada kegiatan inseminasi Buatan (IB) pada peternakan sapi bali di Kecamatan Lalabata Kab. Soppeng.

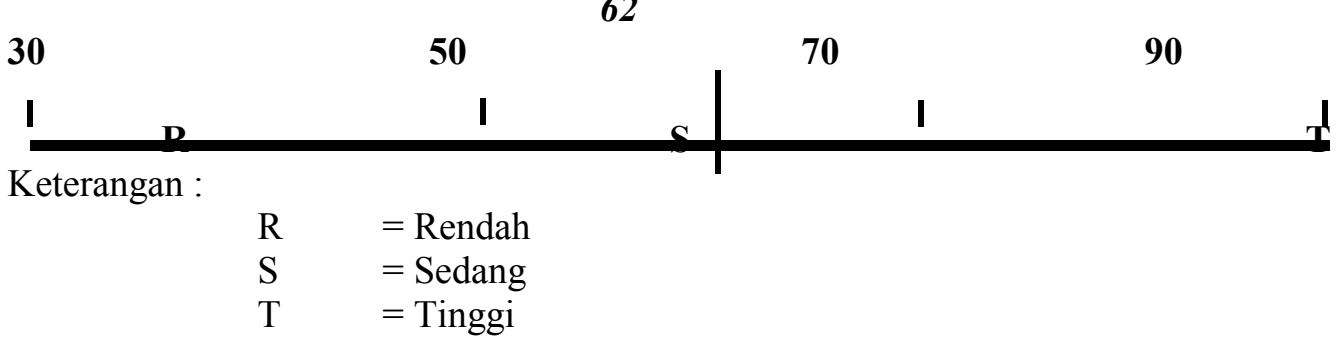

Pada gambar 2 Penilaian adopsi inovasi Teknologi Buatan (IB) mengenai mutu IB pada kegiatan inseminasi Buatan (IB) pada peternakan sapi bali di Kecamatan Lalabata Kab. Soppeng mendapatkan skor 62 berada diantara skor 50 dan skor 70 pada skala sedang

Hasil penelian tersebut didahului dengan hasil penelitian (Demita, 2011) tingkat adopsi IB peternak sapi potong di kecamatan kuranji meyimpulkan bahwa mutu IB dengan membandingkan penerapan dengan rekomendasi yang disampaikan penyuluh, antara lain : Peternak melaksanakan rekomendasi atau anjuran yang disampaikan penyuluh dalam melihat tanda sapi yang berahi dan penerapan IB pada ternak $(+)$ setuju sebesar $100 \%$ yang berarti mutu IB tinggi.

\subsubsection{Luas Penerapan}

Luas penerapan adalah penerapan teknologi IB pada jumlah populasi sapi yang dimiliki peternak sapi potong .Berdasarkan hasil penelitian yang diperoleh tentang penilaian adopsi inovasi mengenai luas penerapan IB pada kegiatan Inseminasi Buatan (IB) di Kecamatan Lalabata Kabupaten Soppeng dapat dilihat pada tabel 4. 
Tabel 4. Penilaian Peternak Terhadap Adopsi Inovasi mengenai luas penerapan IB pada kegiatan Inseminasi Buatan (IB) di Kecamatan Lalabata Kabupaten. Soppeng

\begin{tabular}{lllclc}
\hline No & Indikator & Skor & $\begin{array}{l}\text { Frekuensi } \\
\text { (Orang) }\end{array}$ & $\begin{array}{l}\text { Persentase } \\
(\%)\end{array}$ & $\begin{array}{l}\text { Bobo } \\
\text { t }\end{array}$ \\
\hline 1. & Luas Penerapan teknologi IB diKec. & 3 & - & - & - \\
& Lalabata Kab. Soppeng & 2 & 4 & 13.3 & 8 \\
& & 1 & 26 & 86.7 & 26
\end{tabular}

\begin{tabular}{llll}
\hline Total & 30 & 100 & 32 \\
\hline
\end{tabular}

Sumber : Data Primer Setelah Diolah, 2014

Pada tabel 4, dapat dilihat bahwa total skor adopsi inovasi Teknologi mengenai luas penerapan Inseminasi Buatan (IB) pada peternakan sapi potong di Kecamatan Lalabata Kabupaten Soppeng yaitu sebesar $32 \%$, berada pada kategori Rendah. Hal ini menunjukkan bahwa luas penerapan pada pelaksanaan kegiatan IB di kecamatan Lalabata yakni secara keseluruhan peternak sudah melakukan kegiatan tersebut namun tidak semua ternak yang di peliharanya menerapkan teknologi Inseminasi Buatan (IB). Hal ini di karenakan masih banyaknya peternak yang menggunakan sistem kawin alami dibandingkan penggunaan IB yang disebabkan peternak takut mengambil resiko dan sebagian besar peternak masih dalam tahap mencoba teknologi tersebut dalam skala kecil. Hal ini sesuai pendapat Abdullah (2008) yang menyatakan bahwa permasalahan yang biasa ditemukan di tingkat petani adalah takut mengambil resiko jika gagal.

Hasil penelitan tersebut berdeda dengan hasil penelitian (Demita, 2011) tingkat adopsi IB peternak sapi potong di kecamatan kuranji yang menyatakan luas penerapan IB pada ternak betina antara lain : Peternak hanya menggunakan IB untuk sebagian peternak (-) tidak setuju 100 $\%$, yang berarti bahwa IB telah diterapkan oleh peternak di Kecamatan tersebut.

Untuk lebih jelasnya penilaian luas penerapan dalam kegiatan Inseminasi Buatan (IB) pada peternakan sapi bali di Kecamatan Lalabata Kabupaten Soppeng dapat di lihat pada gambar 3.

Gambar 3. Penilaian adopsi inovasi Teknologi Buatan (IB) mengenai luas penerapan pada kegiatan inseminasi Buatan (IB) pada peternakan sapi bali di Kecamatan Lalabata Kab. Soppeng.

32

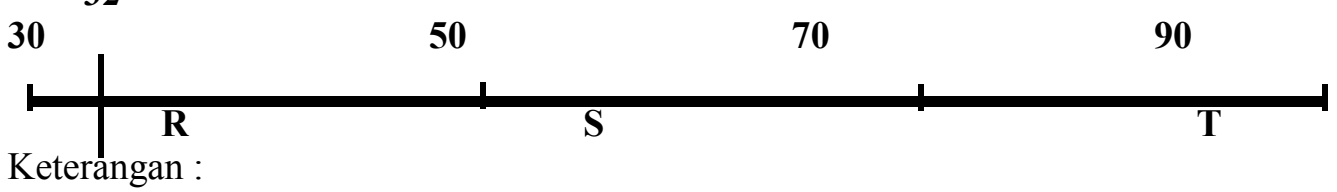

$$
\begin{array}{ll}
\mathrm{T} & =\text { Tinggi } \\
\mathrm{S} & =\text { Sedang } \\
\mathrm{R} & =\text { Rendah }
\end{array}
$$

Pada gambar 3 Penilaian adopsi inovasi Teknologi Buatan (IB) mengenai luas penerapan pada kegiatan inseminasi Buatan (IB) pada peternakan sapi bali di Kecamatan Lalabata Kab. Soppeng mendapatkan skor 32 berada diantara skor 30 dan skor 50 pada skala rendah 


\subsubsection{Tingkat Adopsi Teknologi IB secara keseluruhan}

Hasil penelitian yang diperoleh tentang tanggapan peternak dalam mengadopsi teknologi IB mengenai tingkat adopsi oleh peternak sapi potong diKecamatan Lalabata Kabupaten Soppeng dapat dilihat pada tabel 5.

Tabel 5. Tingkat peternak mengadopsi Teknologi Inseminasi Buatan di Kecamatan Lalabata Kabupaten Soppeng

\begin{tabular}{|l|l|l|l|}
\hline No & Uraian & $\begin{array}{l}\text { Bobot Hasil } \\
\text { Penelitian }\end{array}$ & Persentase (\%) \\
\hline 1 & Waktu yang dibutuhkan & 79 & 45,7 \\
\hline 2 & Mutu IB & 62 & 35,8 \\
\hline 3 & Luas Penerapan & 32 & 18,5 \\
\hline Jumlah & $\mathbf{1 7 3}$ & $\mathbf{1 0 0}$ \\
\hline
\end{tabular}

Sumber : Data Primer setelah Diolah, 2014.

Berdasarkan tabel 5 dapat dilihat bahwa jumlah bobot dari tingkat adopsi teknologi IB (Inseminasi Buatan) yaitu 179 point. Ini menunjukkan bahwa dalam menerima sutau teknologi IB peternak sapi potong di Kecamatan Lalabata kabupaten Soppeng berada pada kategori Sedang, karena pada kategori sedang merupakan kategori dimana peternak belum mengadopsi teknologi IB dengan sepenuhnya karena peternak masih ada menggunakan sistem kawin alami dan sebagian besar peternak menerapkan teknologi tersebut dalam skala kecil karena takut resiko. Hal ini sesuai dengan pendapat Soekartawi (2002) yang berpendapat bahwa peternak melakukan percobaan ide baru tersebut pada skala kecil bila percobaan tersebut berhasil maka peternak akan mencobanya pada skala yang lebih luas. Untuk lebih jelasnya dapat dilihat pada gambar 4.

Gambar 4 . Nilai tingkat adopsi teknologi IB secara keseluhan di Kecamatan Lalabata Kabupaten Soppeng

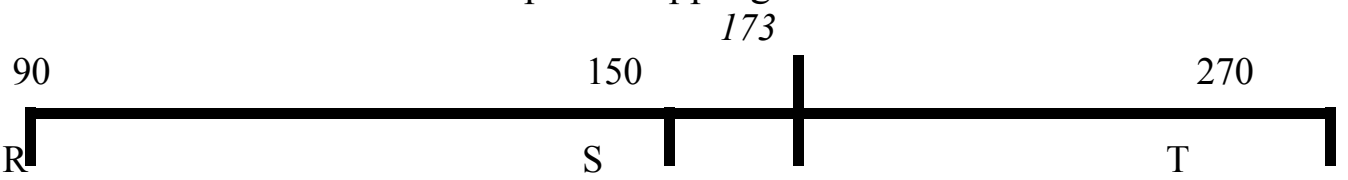

Berdasarkan gambar 4, dapat dilihat bahwa nilai bobot yang diperoleh dari penelitian adalah 173 point yang artinya berada pada kategori sedang. Hal ini dikarenakan peternak sapi potong dikecamatan Lalabata Kabupaten Soppeng mencoba terhadap informasi yang mereka peroleh dan telah memperhitungkan keuntungan dan kerugian serta dihadapkan oleh sebuah problema yang nyata serta ia mencobanya dalam skala kecil. Setelah berhasil dalam percobaannya maka akan menerapkan IB tersebut dalam skala yang lebih besar. Hal ini sesuai dengan pendapat Soekartawi (2002) bahwa, pada tahap mencoba, petani atau individu dihadapkan dengan suatu problema yang nyata. Ia harus secara nyata, menuangkan buah pikirannya tentang ide baru tersebut dalam suatu kenyataan yang sebenarnya. Pemikiran itu harus dituangkan dalam praktek, sesuai dengan apa yang disebut dengan tahapan mencoba dari ide baru, bagaimana ia melakukannya, mengapa harus ia lakukan, dengan siapa ia melakukan ide baru tersebut, apakah dilakukan sendiri atau berkelompok dan dimana ia harus melakukan percobaan itu. Untuk itu kadang-kadang diperlukan bantuan dari pihak lain yang lebih berkompeten agar upaya melakukan percobaan ide baru tersebut dalam skala kecil, adalah tetap berhasil. Hal ini tentu saja dimaksudkan untuk membuktikan keberhasilan eksperimen yang mereka 
lakukan. Bila percobaan ini berhasil dan petani akan mencoba melakukannnya dalam skala yang lebih luas, maka tahapan tersebut disebut dengan tahapan adopsi.

\section{Simpulan}

Tingkat adopsi inovasi teknologi Inseminasi Buatan (IB) pada peternakan sapi potong di Kecamatan Lalabata Kabupaten Soppeng yaitu Tahap waktu yang di butuhkan peternak mulai dari diterimanya informasi sampai pada penerapannya di peroleh berada pada kategori Tinggi dalam arti kemampuan peternak dalam mengadopsi suatu inovasi tergolong cepat,Tahap Luas Penerapan berada pada Kategori Rendah Hal ini menunjukkan bahwa luas penerapan pada pelaksanaan kegiatan IB di kecamatan Lalabata yakni secara keseluruhan peternak sudah melakukan kegiatan tersebut namun tidak semua ternak yang di peliharanya menerapkan teknologi Inseminasi Buatan (IB), dan Tahap Mutu IB berada pada kategori Sedang Hal ini menunjukkan bahwa mutu IB di Kecamatan Lalabata Kabupaten Soppeng yakni hampir secara keseluruhan peternak sudah mengetahui tanda-tanda birahi pada ternaknya sebelum melakukan kegiatan IB

\section{DAFTAR PUSTAKA}

Abdullah, A, 2008.Peranan penyuluhan dan kelompok tani ternak untuk meningkatkan adopsi teknologi dalam peternakan sapi potong,Prosiding seminar nasional sapi potong 24 November 2008. Palu.

Demita, Soekartawi, 2002. Prinsip Dasar Ekonomi Pertanian.Penerbit Rajawali Prdess, Jakarta.A, 2011. Adopsi inovasi Inseminasi Buatan pada peternak sapi potong di Kecamatan Kuranji. Skripsi. Fakultas Peternakan, Uni versitas Andalas, Padang.

Hastuti, D. 2008. Tingkat keberhasilan inseminasi buatan sapi potong ditinjau dari angka konsepsi dan service per conception. Jurnal Fakultas Pertanian Universitas Wahid Hasyim. Mediagro vol.4. No.1. Semarang.

Herawati, T., Anneke Anggraeni, Lisa Praharani, Dwi Utami dan Argi Argiris. 2012. Peran inseminator dalam keberhasilan inseminasi buatan pada sapi perah. Jurnal informatika pertanian, vol. 21 no.2, Desember:81 - 88 .

Riduwan. 2002. Skala Pengukuran Variabel-Variabel Penelitian. Penerbit ALFABETA, Bandung.

Rogers , E.M., R.F. Shoemaker. 1971. Communication of innovation, Second Edition. The Free Press, New York. 